Social Security Benefits For Children With Disabilities

2016

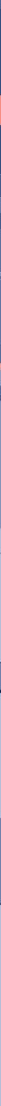




\section{What's Inside}

Contacting Social Security ... 3

Introduction ..........4

Supplemental Security

Income (SSI) payments for children with disabilities. . . . . 4

Social Security Disability

Insurance (SSDI)

benefits for adults

disabled since childhood ... 10

Applying for SSI payments or SSDI benefits and how you can help ...........11

Employment support programs for young people with disabilities ........ 13

Medicaid and Medicare .... 15

Children's Health Insurance Program . . . . . . 16

Other health care services. . . 17 


\section{Contacting Social Security}

\section{Visit our website}

At our website,

www.socialsecurity.gov, you can:

- Create a my Social Security account to review your Social Security Statement, verify your earnings, print a benefit verification letter, change your direct deposit information, and more.

- Apply for Extra Help with Medicare prescription drug plan costs;

- Apply for retirement, disability, and Medicare benefits;

- Get the address of your local Social Security office;

- Request a replacement Medicare card;

- Find copies of our publications; and

- Get answers to frequently asked questions.

\section{Call us}

Call us toll-free at 1-800-772-1213 or at our TTY number, 1-800-325-0778, if you are deaf or hard of hearing.

We provide general information by automated phone service 24 hours a day. You can also use this automated response system to tell us a new address or request a replacement Medicare card. We can answer your case-specific questions from 7 a.m. to 7 p.m., Monday through Friday. You'll generally have a shorter wait time if you call after Tuesday.

We treat all calls confidentially, and a second Social Security representative monitors some telephone calls, because we want to make sure you receive accurate and courteous service. 


\section{Introduction}

This booklet is for the parents, caregivers, or representatives of children younger than age 18 who have disabilities that might make them eligible for Supplemental Security Income (SSI) payments. It is also for adults who became disabled in childhood (prior to age 22), and who might be entitled to Social Security Disability Insurance (SSDI) benefits. (We call this SSDI benefit a "child's" benefit because it's paid on a parent's Social Security earnings record.)

This booklet will help you decide if your child, or a child you know, might be eligible for SSI or Social Security.

\section{Supplemental Security Income (SSI) payments for children with disabilities}

SSI makes monthly payments to people with low income and limited resources who are 65 or older, or blind, or disabled. Your child, if younger than age 18, can qualify if he or she has a physical or mental condition, or combination of conditions, that meets Social Security's definition of disability for children, and if his or her income and resources fall within the eligibility limits. The amount of the SSI payment is different from stateto-state because some states add to 
the SSI payment. Your local Social Security office can tell you more about your state's total SSI payment.

\section{SSI rules about income and resources}

We consider your child's income and resources when deciding if your child is eligible for SSI. We also consider the income and resources of family members living in the child's household. These rules apply if your child lives at home. They also apply if he or she is away at school but returns home from time to time and is subject to your control.

If your child's income and resources, or the income and resources of family members living in the child's household, are more than the amount allowed, we will deny the child's application for SSI payments.

We limit the monthly SSI payment to $\$ 30$ when a child is in a medical facility, and health insurance pays for his or her care.

\section{SSI rules about disability}

Your child must meet all of the following requirements to be considered disabled and, therefore, eligible for SSI:

- The child must not be working and earning more than $\$ 1,130$ a month in 2016. (This earnings amount usually changes every year.) 
- The child must have a physical or mental condition, or a combination of conditions, that result in "marked and severe functional limitations." This means that the condition(s) must very seriously limit your child's activities.

- The child's condition(s) must have been disabling, or be expected to be disabling, for at least 12 months; or the condition(s) must be expected to result in death.

\section{Providing information about your child's condition}

When you apply for SSI payments for your child based on a disability, we will ask you for detailed information about the child's medical condition and about how it affects his or her ability to perform daily activities. We also will ask you to give permission to the doctors, teachers, therapists, and other professionals who have information about your child's condition to send the information to us.

If you have any of your child's medical or school records, please bring them with you. This will help speed up the decision-making process.

\section{What happens next?}

We send all of the information you give us to the Disability Determination Services office in your state. Doctors and other trained staff in that state agency will review the 
information, and will request your child's medical and school records, and any other information needed to decide if your child meets our criteria for disability.

If the state agency can't make a disability determination using only the medical information, school records, and other facts they have, they may ask you to take your child for a medical examination or test. We will pay for the exam or test.

\section{We may make immediate SSI payments to your child}

The state agency may take three to five months to decide if your child meets our criteria for disability. For some medical conditions, however, we make SSI payments right away, and for up to six months, while the state agency decides if your child has a qualifying disability.

Following are some of the conditions that may qualify:

- HIV infection

- Total blindness

- Total deafness

- Cerebral palsy

- Down syndrome

- Muscular dystrophy

- Severe intellectual disability /child age 7 or older)

- Birth weight below 2 pounds, 10 ounces 
If your child has one of the qualifying conditions, he or she will get SSI payments right away. If the state agency ultimately decides that your child's disability is not severe enough for SSI, you won't have to pay back the SSI payments that your child got.

\section{SSI disability reviews}

After your child starts receiving SSI, the law requires that we review your child's medical condition from time to time to verify that his or her disability still meets our criteria. We must do this review:

- At least every three years for children younger than age 18 whose conditions are expected to improve; and

- By age 1 for babies who are getting SSI payments because of their low birth weight. If we determine their medical condition isn't expected to improve by their first birthday, we may schedule the review for a later date.

We may perform a disability review even if your child's condition isn't expected to improve. When we do a review, you must present evidence that your child's disability still severely limits his or her daily activities and that your child has been receiving treatment that's considered medically necessary for his or her medical condition. 


\section{What happens when your child turns age 18}

In the SSI program, a child becomes an adult at age 18, and we use different medical and nonmedical rules when deciding if an adult can get SSI disability payments. For example, we don't count the income and resources of family members when deciding whether an adult meets the financial limits for SSI. We count only the adult's income and resources. We also use the disability rules for adults when deciding whether an adult is eligible for SSI.

- If your child is already receiving SSI payments, we must review the child's medical condition when he or she turns age 18. We usually do this review during the one-year period that begins on your child's 18th birthday. We will use the adult disability rules to decide whether your 18-year-old is disabled.

- Even if your child wasn't eligible for SSI before his or her 18th birthday because you and your spouse had too much income or too many resources, he or she may become eligible for SSI at age 18.

For more information, read Supplemental Security Income (SSI) (Publication No. 05-11000). 


\section{Social Security Disability Insurance (SSDI) benefits for adults disabled since childhood}

The SSDI program pays benefits to adults who have a disability that began before they became 22-yearsold. We consider this SSDI benefit as a "child's" benefit because it's paid on a parent's Social Security earnings record.

For a disabled adult to become entitled to this "child" benefit, one of his or her parents:

- Must be receiving Social Security retirement or disability benefits; or

- Must have died and have worked enough to qualify for Social Security.

These benefits also are payable to an adult if he or she is disabled at age 18 , and if they received dependents benefits on a parent's Social Security earnings record prior to age 18 . We make the disability determination using the disability rules for adults.

SSDI disabled adult "child" benefits continue as long as the individual remains disabled. Your child doesn't need to have worked to get these benefits. 


\section{How we determine if your "child" is disabled and entitled to SSDI benefits}

If your child is age 18 or older, we will evaluate his or her claim and determine disability in the same way we would determine disability for any adult. We send the application to the Disability Determination Services in your state that makes the disability determination for us. For detailed information about how we determine disability for adults, read Disability Benefits (Publication No. 05-10029).

\section{Applying for SSI payments or SSDI benefits and how you can help}

You can apply for SSI payments or SSDI benefits for your child by calling Social Security toll-free at 1-800-772-1213 or by visiting your local Social Security office. If you are applying for SSI payments for your child, you should have his or her Social Security number and birth certificate with you. If you are applying for SSDI benefits for your child based on your own earnings record, please have your own Social Security number with you, or the Social Security number of the retired, disabled, or deceased parent on whose record the SSDI claim is being filed, in addition to the child's Social Security number and birth certificate. 
You can help us make a determination by:

- Telling us as much as you can about your child's medical condition(s);

- Giving us the dates of visits to doctors or hospitals, the patient account numbers for any doctors or hospitals, and any other information that will help us get your child's medical records; and

- Providing us with copies of any medical reports or information you have in your possession.

NOTE: You don't need to request information from your child's doctors. We will contact them directly for reports or information that we need to make a decision about your child's disability.

If your child is younger than age 18 and applying for SSI, you must provide records that show your income and resources, as well as those of your child. We also will ask you to describe how your child's disability affects his or her ability to perform daily activities. In addition, we will ask for the names of teachers, day care providers, and family members who can provide information about how your child functions. If you have school records, you should bring them to the interview.

In many communities, special arrangements have been made with medical providers, social service 
agencies, and schools to help us get the evidence we need to process your child's claim. Your cooperation in getting records and other information, however, will help us finish our job more quickly.

\section{Employment support programs for young people with disabilities}

We have many ways to encourage young people who are receiving SSI payments or SSDI benefits and who want to go to work.

\section{Under SSI:}

- When we figure your child's monthly SSI payment, we don't count most of your child's income. If your child is younger than age 22 , and is a student who regularly attends school, we exclude even more of his or her earnings each month. In 2016, disabled students younger than age 22 may exclude $\$ 1,780$ of their monthly earnings, with an annual limit of $\$ 7,180$, when counting their income for SSI. These limits may increase each year.

- With a Plan to Achieve Self-Support (PASS), a child who is age 15 or older can save some income and resources to pay for education and other things needed to be able to work. We don't count the saved income when we figure your child's 
income for SSI. We don't count the saved income and resources when we figure the amount of your child's payment.

- Because of a medical condition(s), your child may need certain items and services to work, such as a wheelchair or a personal assistant. When figuring your child's SSI payment, we won't count some, or all, of the amount paid for these items and services in your child's earnings.

- Your child older than age 15 may get help with rehabilitation and training.

- Medicaid coverage will continue even if your child's earnings are high enough to stop the monthly SSI payment as long as the earnings are under a certain amount.

\section{Under SSDI:}

- An adult disabled before age 22 can get the same help with work expenses explained above for an SSI child, and help with rehabilitation and training.

- Cash benefits may continue until the individual can work regularly.

- Medicare may continue for up to 93 months (seven years, nine months).

You can get more information about these programs at our website, WWw.socialsecurity.gov, or by calling us toll-free at 1-800-772-1213. 


\section{Medicaid and Medicare}

Medicaid is a health care program for people with low incomes and limited resources. In most states, children who get SSI payments qualify for Medicaid. In many states, Medicaid comes automatically with SSI eligibility. In other states, you must sign up for it. And some children can get Medicaid coverage even if they don't qualify for SSI. Check with your local Social Security office, your state Medicaid agency, or your state or county social services office for more information.

Medicare is a federal health insurance program for people age 65 or older, and for people who have been getting Social Security disability benefits for at least two years.

There are two exceptions to this rule. Your disabled adult child can get Medicare immediately if he or she:

- Has a chronic renal disease and needs a kidney transplant or maintenance dialysis; or

- Has Lou Gehrig's disease (amyotrophic lateral sclerosis). 


\section{Children's Health Insurance Program}

The Children's Health Insurance Program enables states to provide health insurance to children from working families with incomes too high to qualify for Medicaid, but too low to afford private health insurance. The program provides coverage for prescription drugs, vision, hearing, and mental health services, and is available in all 50 states and the District of Columbia. Your state Medicaid agency can provide more information about this program, or you can get more information about coverage for your children at www.insurekidsnow.gov on the Internet or by calling 1-877-543-7669. 


\section{Other health care services}

When your child gets SSI, we'll refer you to places where you can get health care services for your child. These services are under the Children with Special Health Care Needs provision of the Social Security Act. State health agencies usually manage these programs.

States call these services by many different names, including Children's Special Health Services, Children's Medical Services, and Handicapped Children's Program. Most programs provide services through clinics, private offices, hospital-based outpatient and inpatient treatment centers, or community agencies.

Even if your child doesn't get SSI, one of these programs may be able to help you. Local health departments, social service offices, or hospitals should be able to help you contact your local Children with Special Health Care Needs program. 
Notes

18 S o c i a 1 S e curity


Notes 


\section{www.socialsecurity.gov}
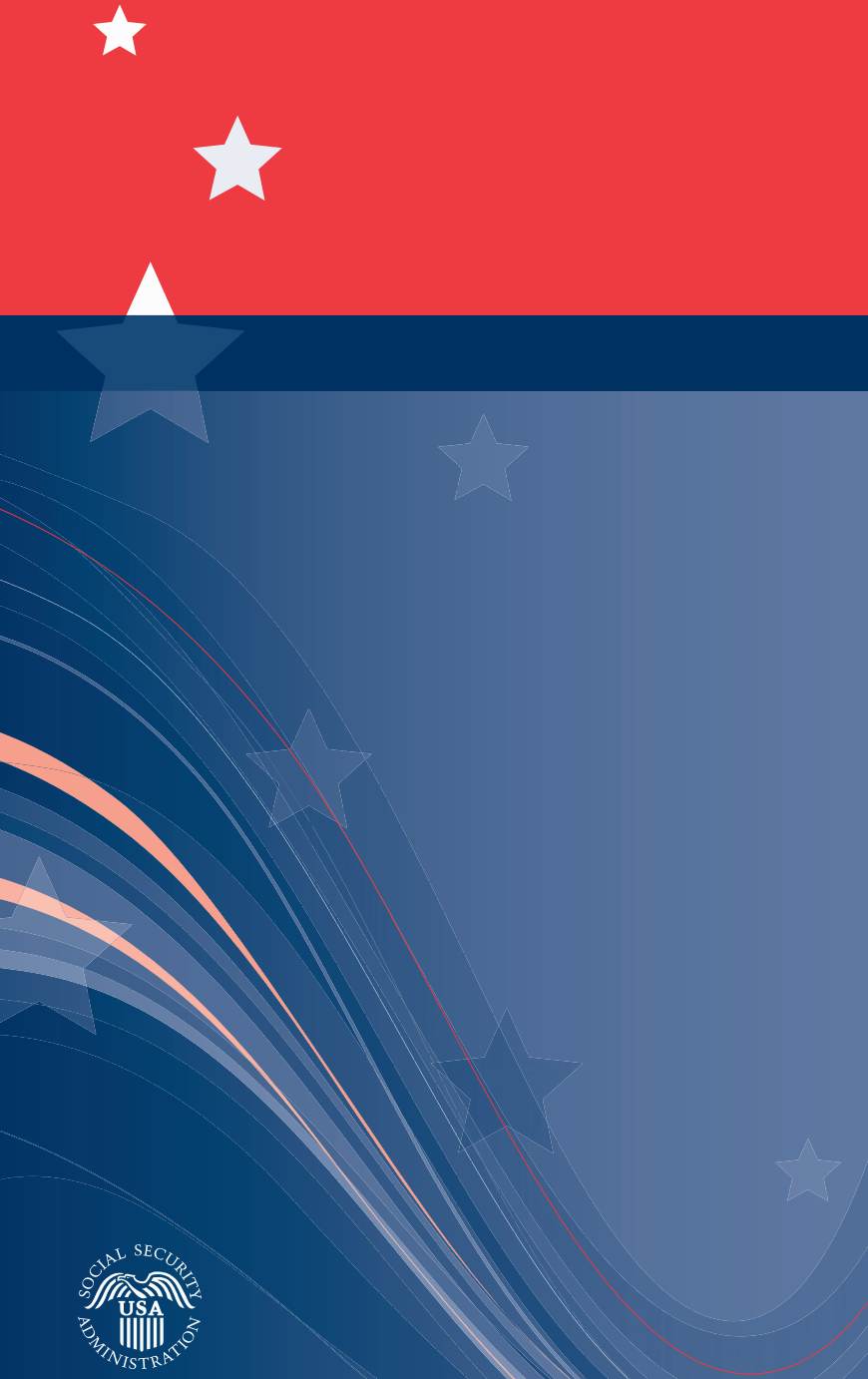

Social Security Administration

SSA Publication No. 05-10026

ICN 455360

Unit of Issue - HD (one hundred)

January 2016 (Recycle prior editions)

Produced and published at U.S. taxpayer expense

Printed on recycled paper 